\title{
1 Rationale and theoretical considerations
}

\subsection{Migration System Theory: the case of the EU-Western Balkans migration system}

For obvious reasons, the attempt to tie together different aspects of migration such as integration and transnationalism - that links the origin and destination countries needs a clearly elaborated analytic framework. In addressing the issue, our approach is based on the argument that these complex processes take place within migration systems that connect countries and regions. We adopt the migration systems approach mainly as an analytical framework at macro level for the comparative research of Albanian migration in Austria and Greece, with the latter serving as a typological paradigm of the EU-Western Balkans migration system.

In this context, a migration system is conceptualized as two or more places (see nation states) connected to each other by flows and counter-flows of people, goods, services, and information (MabogunJe 1970; FAist 1995; DE HAAS 2009). This, in turn, would lead to situations of quasi-organized migratory flows (MABOGUNJE 1970), which by linking people, families, and communities over space, often results in a "geographical structuring and clustering of migration flows" (DE HAAS 2009, p. 9). Of course, by focusing on individual processes within a migration system, mobility is viewed as a dynamic human trajectory of movement cutting across time and space strata (BOYD 1989, p. 641). Therefore, instead of perceiving migration as a linear, unidirectional, push and pull and cause-effect movement, it is rather understood as a synthesis of transnational, inter-connected, complex and self-modifying systems in which the "effect of changes in one part can be traced through the entire system" (FAIST 2010, p. 65).

Traditionally, the migration systems narrative has viewed migrants' settlement as an end state based on the assumption that once migrants have settled at the country of destination, migration becomes self-perpetuating, since it tends to establish socioeconomic structures (see e.g. networks), which are able to sustain the process phenomenologically (CAStles and Miller 2009; MAssey 1990; Bakewell et al. 2011, p. 6). This approach, however, pays little attention to a range of determinant factors. These include: (a) The contextual dynamics that take place both in receiving countries and in countries of origin, changing the initial socio-economic conditions under which migration was unfolded (DE HAAS 2010) (e.g. the Greek economic crisis). (b) The formation of a wide range of networks (e.g. transnational, ethnic, social) (FAIST 1997). (c) The role of migrants' agency in developing new strategies for responding to the new, changing situation (GEMI 2014, p. 13). 
Therefore, by taking into consideration the above, we conceptualize migration systems as complex and multi-faceted processes distinguished by: (a) The heterogeneity and multiple dynamics of migration trajectories. (b) Changes and socio-economic transformations (e.g. economic crisis, stagnation) occurring in a migration system. (c) Strong networks. (d) The active role of migrants' agency (vis-à-vis structure). Our aim is to address the above issues by comparing two different national and local contexts within the same migration system. By focusing on the EU-Western Balkans migration system, the study seeks to bring a new understanding to one of the most representative cases, namely that of Albanian migration (Western Balkans). Two different migration and integration regimes, namely Greece and Austria (EU destination countries), are compared. Before diving deeper into the key features of the EU-Western Balkan migration system, it will be useful to reflect on the most important theoretical approaches on migration systems.

\section{Migration systems theory: an overview}

It is commonly acknowledged that economic and labour market opportunity factors have always played a substantial role in explaining the typology of international migration. That alone is not enough to interpret the mobility patterns and geographically structured morphology of migration (DE HAAS 2009, p. 4) that connect particular locations, places and regions in countries of both origin and destination. Linked to this, the core argument framing SKELDON's approach (1997) maintains that there is a solid interconnection among the level of economic development, state formation, and patterns of population mobility (in DE HAAs 2010, p. 7). It is further supported that an integrated migration system, which includes global and local migration flows, emerges if the above level of interconnection (or interdependency) is high and dense. Conversely, if it is low, the migration systems are not integrated and migration flows principally remain local (SKeLdOn 1997, p. 52). The question arises, however, whether this is enough to explain the emerging of migration systems. According to DE HAAS (2010, p. 8) what leads to the formation of migration systems is exactly the functional combination of economic and demographic elements along with high levels of connectivity (dependency) between 'core' and 'peripheral' countries (deriving from Wallerstein's world systems theory 1979), with the latter providing for a cheap and flexible labour force. In the same vein, the founding father of migration systems theory, the geographer AKIN MABOGUnJE (1970), focused in particular on the role of feedback mechanisms that tend to strengthen and pattern these initial structural interdependencies between the two ends (core versus periphery). It is exactly these feedback mechanisms that enable the mobility of people between particular cities, countries, and regions, together with the subsequent flow of goods, capital, ideas, and information (BAKEwell 2012, p. 7). Ultimately, the result is a highly patterned typology of relatively stable mobility of people between particular countries and/or regions, which creates an identifiable geographic structure that persists 
across space and time (MASSEY et al. 1998, p. 61). In an attempt to address the use of different aspects of the migration system, BAKEwELL (2012) distinguishes among different forms: embedded functionalist, defined functionalist, skeletal, feedback, and abstract systems. Interestingly, the embedded functionalist form seems to be quite close to our approach as it refers to the migration system as a self-regulating mechanism within a wider social system, which tend to be qualified by the nature of its very specific systemic features such as the labour migration system or the guest-worker system (BAKEWELl 2012, p. 5).

As mentioned above, migration systems are associated primarily with the idea that once a significant number of migrants have settled at the destination, migration becomes self-perpetuating as it enables the formation of socio-economic structures (i.e. networks) to sustain and generate the process (CAstles and Miller 2009; MAssey 1990; BAKewell et al. 2011, p. 6). In the light of this, it is suggested that it is the migration network theory that provides a better analytical explanation for the emergence of migration systems (BAKewell et al. 2011, p. 10; FAist 2000; MASSEY et al. 1993).

Specifically, migration network theory lays a strong emphasis on explaining how the past migration experience, the settled migrants, and established ethnic communities in particular countries of destination facilitate the arrival of new migrants (DELECHAT 2002; STARK and WANG 2002). In fact, it is commonly known that the social capital embedded within migrant networks in receiving countries lower the costs and risks of migration movements, hence increasing the likelihood of new migration flows (BASHI 2007).

In order to better understand how individual and family migration evolved into migration networks capable of shaping entire local and regional migration systems, it would be useful to consider GRANOVETTER's (1973) theory about the relevance of weak and strong ties (KOHLBACHER 2017, p. 168) and in particular the hypothesis of the 'strength of weak ties' (DE HAAS 2009, p. 27). Later known as 'bonding' and 'bridging' social capital (PutNAm 2000), the weak ties (bonding) refers to the high level of in-group homogeneity, while strong ties (bridging) is generally attributed to increasing intercommunity and intergroup communication and cohesion within a given society.

Further elaborating on the issue, PORTEs (1996) makes an additional point assuming that strong intra-group and intra-community ties (weak ties or bonding social capital) have the potential to produce negative social outcome by excluding outsiders (DE HAAS 2009 , p. 28). The hypothesis of the 'downside of social capital' elaborated by PORTES (1996) maintains that 'strong bonding' and 'weak bridging' social capital tends to act as barriers to socio-economic integration and social mobility. The relevance for the theory of migration systems consists in the hypothesis that a certain degree of balance between bonding (weak ties) social capital and bridging (strong ties) would be a necessary prerequisite for the formation of migration systems from the point when migration movements gain their own momentum (DE HAAS 2009, p. 28). This approach, however, is considered not to pay enough attention to the structural or contextual implications 
that migration flows have, both for the sending and receiving countries' context on the macro -level. Yet, it hardly takes into account the change of the initial conditions under which migration once took place (DE HAAS 2010) as for example an economic crisis (i.e. Greece), unemployment, decrease in remittances (i.e. Albania), and an unstable legal status (i.e. the case of Albanian migrants in Greece) (BAKEwELL et al. 2011).

The question, however, is how to explain the changes occurring in a migration system as well as the role of agency vis-à-vis structure in addressing such change (BAKEwELL et al. 2011). In this case, to be an agent implies to be able to exercise a certain degree of control over both structural factors and social relations. Of course, one may acknowledge that the action of agency at micro -level is framed and to a great degree determined by the legal status and opportunity structures established historically by the (national) context within which migrants exercise their own agency. However, the role of agency is indeed essential to the outcome of migration processes and concomitant socio-economic relations at macro and meso -level, as migrants have no choices but to develop new strategies and delve into alternative pathways in response to policies and structural restriction that condition their upward mobility.

Apparently, migration systems do not emerge solely due to a single migration movement per se. They rather establish themselves as the result of a cumulative causation effect linked to past migration corridors (MASSEY et al. 1993), with settled migrants generating chain migration flows. These evolve over the years into transnational communities that create further mainstreaming migration flows (DoOMERNIK and KYLE 2004, p. 266). It therefore seems reasonable to consider the migration network as a key variable for the cumulative causation hypothesis (BAKEwELL 2012, p. 8). According to MASSEY (1990), the concept of cumulative causation refers to the idea that migration brings about changes in socio-economic structures that "make additional migration likely" (p. 6). The cumulative causation argument, as elaborated by Massey, brings out an additional contextual feedback mechanism that goes beyond the receiving countries' reality. As far as sending countries are concerned, one may assume that emigration flows exert negative impacts on the economic structures of those countries (i.e. Albania) and of entire regions (i.e. Western Balkans). This happens mainly through the expatriation or loss of their human ('brain drain') and other capital resources, which particularly increases or perpetuates their dependency on the outside world (DE HAAS 2009, p. 10). This, in turn, could lead to the emergence of a 'culture of migration' (MASSEY et al. 1993, p. 453) which is usually strongly associated with individual socio-economic success, thereby turning migration into an increasing trend or even mainstreaming it as a prevailing social norm. As a consequence, it is possible to generate self-sustaining mobility by further cultivating aspirations which can be materialized through established migration pathways, facilitated by migrant networks that minimize the costs and risks of migrating (DE HAAS 2009, p. 11).

Returning to the subject at hand, the question is what advances have taken place in migration system theories that might enhance our understanding of the EU-Western 
Balkans migration system. The first aspect that needs to be addressed is that of dealing with a system: the focus automatically shifts to its constituent parts, such as the analysis of countries of both origin and destination. The contextual dynamics that connects countries of origin and destination, and migration flows should also be considered. Furthermore, intervening factors such as migration institutions or/and policies are of interest, and it is important to find out how experience of migration in a given period may create the necessary conditions for chain migration and future movements to take place. The migration systems approach enables the researcher to consider various levels of analysis. The contribution of this approach lies in the fact that it dialectically ties together the action of migrant agency with the changes taking place within the wider social system (BAKEWELL 2012, p. 9). A synthesis of different migration systems profiles contains the following elements:

(a) A set of interacting elements (e.g. flows of people, ideas and goods).

(b) Social institutions embedded in the 'culture of migration'.

(c) Strategies employed by particular actors (e.g. individuals, households, policy making and civil society organisations) at both ends (locations or countries).

(d) A general socio-economic dynamics that shapes the ways in which the above elements change as a response to transformations taking place in both feedback mechanisms and the wider environment (BAKEWELL 2012, p. 4).

From a dialectical viewpoint, the decline of such systems should also be considered. According to DE HAAs (2010, p. 30), that may happen if:

(a) migrant communities start to experience socio-economic upward mobility that usually is associated with increasing integration and/or assimilation, geographical dispersal, and the reduction of clustering,

(b) additional legal migration restrictions are imposed, resulting in increased costs of migration and the creation of negative social capital for settled migrants, and

(c) there is a substantial reduction of socio-economic opportunity gaps between origin and destination countries.

One may further assume that, when faced with the rupture of co-ethnic networks, migration flows may not necessarily decrease, but might be more likely to shift to new destinations (DE HAAs 2009, p. 30). The case of Albanians in Greece might again serve as an example here. On the other hand, the decline of (new) migration flows that occurs because of integration and assimilation processes, does not necessary mean the end of a migration system (ibid.). Integration and assimilation processes imply the decrease of bonding social capital and increase of bridging social capital. 'Strong' ethnic groups can sustain transnational relations and develop transnational identities, which have the potential to become trans-generational and 'diasporic' (COHEN 1997, p. x). In fact, several studies have indicated that integration (or assimilation) necessarily goes along with declining transnational ties, or vice versa (GUARNizo et al. 2003, FoKKEMA et al. 
2012; ItZigsohn and Giorgul SAUCEDo 2002). In particular, migrant groups that combine successful economic integration with limited cultural assimilation and the maintenance of a strong group identity seem to represent a high potential for network migration (DE HAAS 2009, p. 30).

Summarizing, the migration systems approach allows for the conceptualization of migration moving beyond a linear, unidirectional, push-pull movement. Its advantages arguably lie in the description of the migration phenomenon as circular, multi-causal and interdependent, with the effects of change in one part of the system being traceable through the rest of the system (FAIST 1997, p. 193). Therefore, migration systems can be (a) self-feeding through chain migration, (b) self-regulating because of their ability to shape their dynamics according to the scale and magnitude of the systemic crisis, and (c) self-modifying through the shift of migration flows to a different destination when the initial destination has been exhausted (KING 2012).

\section{Insights from the EU-Western Balkans migration system}

The migration systems approach as elaborated above is assumed to create a common framework for understanding migration to Europe in terms of various interconnections between geographical areas (countries) and the concomitant causes and effects of migration. As we have seen so far, the fundamental assumption of migration systems theory is that migration brings substantial change to the social, cultural, economic, and institutional fabric at both the sending and receiving ends, setting up the conditions for the development of a cross-national space within which migration processes are unfolded (DE HAAS 2017, p. 5). In terms of EU migration systems and subsequent integration models, there is a high degree of heterogeneity between countries, which is reflected in a typological scheme that consists of four main groups (MEDAM 2017, p. 5):

(a) Southern EU countries, which include relatively recent immigration countries, namely Greece, Portugal, Italy, and Spain.

(b) North-western EU countries, which include long-standing EU immigration countries: Austria, Belgium, Luxembourg, the Netherlands, Germany, France, and the United Kingdom.

(c) Scandinavian countries that are known for their generous welfare systems: Sweden, Finland, and Denmark.

(d) New EU accession countries: Bulgaria, Cyprus, Croatia, Czech Republic, Estonia, Latvia, Lithuania, Hungary, Malta, Romania, Poland and recently Croatia.

With respect to integration policies, the level of heterogeneity among the above countries seems to be even greater. The high level of variation in the terminology used to design policies that largely mirror the perception of the 'other' within national ideology, serves as an indication of this heterogeneity. This can be illustrated regarding largely instrumental concepts such as 'guest worker', 'minority', 'race relations', 'assimilation', 
'multiculturalism', 'integration', and 'citizenship'. It is exactly this heterogeneity of migration realities in Europe that gives shape to different migration sub-systems. The emergence and evolution of such sub-systems are a result of the high level of interconnectedness between the migration dynamics (deriving from the historical context and its present forms) and economic, political and cultural backgrounds (AUDEBERT and KAMEL DORAI 2010, p. 35). The geography of European migration sub-systems confirms the hypothesis of 'privileged' relations between receiving and sending countries that are largely linked by cultural and political affinities historically rooted in these countries (FASSMANN and MüNZ 1992, p. 464). Consequently, the above-mentioned international links create the necessary background for the development of specific migration policies particularly on the part of receiving countries. These links include guest-worker recruitment systems or selective approaches to the granting of rights to certain nationalities. In fact, these double standard policies have played a crucial role in giving impetus to and definitely shaping initial migration patterns, which later tended to develop their own momentum through the self-perpetuating dynamics channelized by migrant networks (DE HAAS 2017, p. 35).

In the context of the sub-system of Western Balkan migration to the EU, there have been several attempts to explain the migration processes theoretically, using the specific conditions and the geography of the region as points of reference. In general, the dynamics that have shaped the geographical trajectories of migration corridors in the region have been attributed to the interconnection of four factors: (a) The history of the region. (b) The historical relationships and cultural linkages between both subsequent Western Balkan countries and (today) EU countries. (c) The pre-existence of migrant networks. (d) (Selective) migration policies particularly applied by receiving countries (KUPISZEWSKI et al. 2009, p. 9). Western Balkan migration patterns seem to have been shaped by a combination of certain general and specific factors such as:

(a) The ethnic complexities and related historical controversies that often fuelled inter-ethnic conflicts. If we look deeper at the push and pull factors, it is clear that during the wars in Bosnia-Herzegovina and later in Kosovo in the 1990s, the factors that pushed people to flee their countries ravaged by the war were lifethreatening conditions and ethnic cleansing (KuPISZEWSKI et al. 2009, p. 27).

(b) The economic transformation that followed the systemic collapse of communist regimes. This collapse was followed by a model of planned economies in the region, or the so-called socialist self-management model applied in former Yugoslavia. The transition took place by the end of the1980s and at the beginning of the 1990s and it represented the transition to a modern competitive economic system.

(c) Political actors who, by fuelling nationalistic sentiments and long-standing interethnic rivalries, caused the destabilization of the entire region, as can be seen in the practices of 'ethnic cleansing' in Bosnia-Herzegovina and Kosovo during the 1990s. 
Migration, however, was not a new phenomenon for the countries of the Western Balkans emerging in the 1990s. In fact, almost all countries of the region (with Albania being an exception) have traditionally been source countries of labour emigration to Europe. Through the guest-worker recruitment bilateral scheme (e.g. with Germany and Austria), emigration of the citizens of the former Yugoslavia continued even during the cold war era. In fact, in contrast to Albania where under the communist regime the freedom of (both internal and external) movement was strictly withheld, the former Yugoslav Federation had granted a relative freedom of movement to its citizens. The fall of the Iron Curtain however fundamentally changed the dynamics in the entire region by transforming its countries almost overnight in migrant sending countries whose citizens entered the EU in great numbers and under a number of preconditions, for instance on humanitarian grounds, as asylum seekers, or as labour migrants.

Despite the common ground, the region is quite diverse with neighbouring countries differing politically and economically, but also in terms of their historical and cultural developments. Furthermore, any degree of regional unity or commonalities of national migration experiences could hardly be assumed, especially in the light of geographical diversification among the receiving EU countries. This is illustrated by the fact that the guest-worker regime applied in the 1960s and 1970s contributed to the negative migration balance in the region with former Yugoslav citizens recruited as temporary, low-skilled workers in Germany and Austria (FASSMAnN 2017, p. 126). At the beginning of the1990s, rapid developments set in. They were marked firstly by a largescale emigration from Bosnia-Herzegovina (as a consequence of the Balkan wars) to Austria and Germany. Along with that, the movement of Albanians to two neighbouring EU countries, Greece and Italy, assumed the proportions of a 'biblical exodus' in the aftermath of the collapse of the authoritarian regime. These developments definitely reshaped the dynamics of contemporary migration from the Western Balkans to the EU. In 2000, the effects of the Balkan wars were still noticeable, a fact which was witnessed to by the significant numbers of migrants from Croatia and Bosnia-Herzegovina in Germany and Austria (BALDwIN-EDwARDs 2004, p. 9; MEDAM 2017, p. 5).

Varying migration categories and motivations exist across the Western Balkan region, also making them difficult to generalise. Nonetheless, since the 1990s, four types of migration have been identified. These involve: (a) Forced migration associated with war and ethnic cleansing (BALDwIN-EDwARds 2006, p. 3). (b) Ethnic migration that emerged as a combination of 'voluntary repatriation' to the 'ancient motherland' (e.g., the case of Albanians of Greek descent [omogeneis] fleeing to Greece at the beginning of the 1990s or Aussiedler in Germany) and special benefits derived from their privileged status (e.g., a special pensions scheme) compared to that of other migrants. (c) Human trafficking, which is presumably the greatest scourge on the contemporary history of the region. (d) Labour migration, which has taken on several regular or irregular forms (i.e. circular migration mainly involving semi-skilled and unskilled persons), including here the newly emerged category of (economic) asylum seekers. In 2015, over 130,000 
migrants from Kosovo, Albania, and Serbia applied for refugee status in the EU, with Germany being at the top of the preferred destination countries (ZENELI 2017).

In demographic terms, since the fall of Iron Curtain, population figures in the region have significantly dropped, largely due to mass emigration. At the beginning of the 1990s, the war in Croatia and Bosnia-Herzegovina created the largest single wave of emigration. Of the 2.2 million people who were forced to leave their home towns and villages, roughly 375,000 had emigrated to Central and Western Europe by mid-1992. Albania, on the other hand, has one of the world's highest emigration rates, in relation to its population, with a stock of emigrants nearly $39 \%$ of the total population (UNDESA 2015). Today, there are around 800,000 Albanian regular migrants living in Greece and Italy (353,826 in Greece as of April 2018, cf. Greek Ministry of Migration Policy 2018 and 442,838 in Italy in 2017, cf. Italian Ministry of Labour and Social Policies 2017). In Austria, the largest migration population is from the Western Balkans, with Serbia $(181,700)$, Bosnia and Herzegovina (94,000), and the Former Yug. Rep. of Macedonia $(21,700)$ ranking among the 15 top nationalities in the country (OECD 2017; STATISTICS Austria 2017).

It is clear that the political and socio-economic upheaval or transformation that the region of the Western Balkans have experienced since the1990s would be impossible to understand without considering the crucial role of mass migration outflows towards the EU countries particularly since the1990s. Of course, this large-scale migration has also profoundly shaped the socio-economic determinants in origin countries located at the EU South-East borders (DE HAAS 2017). In particular, migration seems to have been extremely beneficial for the economies of the Western Balkans with remittances playing the most significant role in their economies. It is estimated that remittances contribute more than 10\% of the GDP of the Western Balkans (ZeNELI 2017). In addition, they are supposed to boost small and medium enterprises, to support local consumption and contribute to the welfare system in absence of public social policies (ibid.). On the other hand, the phenomenon of brain drain of the young, the skilled, and the highly skilled has largely influenced the pace of development as well as the overall competitiveness of the region, which in turn seems to have slowed down the convergence of the economies of the Western Balkans with the rest of Europe.

Generally speaking, the region remains far behind the EU, with old rivalries and unsettled political issues remaining serious barriers. In terms of development, according to the World Development Indicators of the World Bank, the countries of the region remain very low in terms of GDP per capita compared with the EU average (as of 014): Albania: 12.5\%; FYROM at 15\%; Montenegro at 20\% and Kosovo (under UN Security Council Resolution 1244) at 11\% (in nominal terms). Countries are still fragmented in terms of infrastructure connections, and the willingness to move faster towards a common economic area is lacking. During the last financial crisis in Southern EU countries such as Greece and Italy, a point at which most of the Albanian migrants were already settled, a considerable number of migrants returned home. According to official 
statistics of the Albanian authorities (Albanian Ministry of INTERIor 2015), 133,544 Albanian emigrants above 18 years of age have returned to Albania during the period 2009-2013.

Over the last decade, the EU-Western Balkans migration system seems to have entered into a transition period. The Western Balkan countries are undergoing two transitions: the first is the transition from a region of unstable migration patterns to a region with relatively stable migration at a much lower level, which is also much more predictable. The second is the transition from a region of emigration to one of mixed transit flows. Hundreds of thousands of asylum seekers and migrants arrived in the European Union via the Western Balkans in 2015-2016 alone, turning the region into a very important transit hotspot. At the supranational level, the boundaries between the EU and Western Balkan countries have become increasingly blurred, and the striking diversification and diffusion of migration itineraries point at the growing complexity of migration systems. Apart from being neighbouring countries, the Western Balkan countries of Serbia, Albania, Bosnia and Herzegovina, FYROM, Montenegro and Kosovo $^{2}$ are also EU candidate countries, their citizens hence falling into the category of so-called 'third-country nationals' (FASSMAnN 2017, p. 122). Apart from the role of the subsequent national migration policies, the EU migration policy and the EU-Western Balkan cooperation on migration have also been of crucial importance in shaping the migration system. EU-Western Balkan cooperation is part of the Stabilisation and Association Process (SAP) of EU relations with the Western Balkans (KuPISZEwSKI et al. 2009, p. 9). Indeed, the cooperation process on migration policy between the EU and the region has led to a considerable Europeanization of migration policies of Western Balkan countries, particularly focused on the control of irregular migration.

In conclusion, we adopt the migration systems approach mainly as an analytical framework for our study on Greece and Austria. In this context, a migration system is defined as a set of sending and receiving countries experiencing similar in- and out-flows and sharing some common socio-economic and political features. In this vein, migration from the Western Balkans to the EU is conceptualized as (a) an integral part of broader historical and socio-economic transformation processes that had taken place in the region, in particular since the 1990s. It (b) also has its internal, self-sustaining and self-undermining, endogenous dynamics, which (c) affects such processes of change in its own right.

2 Croatia joined the EU in July 2013. 


\title{
1.2 Conceptualizing the dynamic interaction of integration and transnationalism
}

\author{
Integration vis-à-vis transnationalism
}

It has been widely acknowledged that the theory of transnationalism has changed the understanding of migrants' cognitive geographies and their pathways of integration and patterns of mobility (VATHI 2015, p. 117). Some scholars support the idea that integration and transnational transfers can be complementary, in particular in the case of economic integration (FoKKema et al. 2012; GuARnizo et al. 2003; ItZigsohn and Giorguli SAUCEDo 2002), while others question the assumed positive relation between migrants' integration and transnationalism (FAIST 2000; PORTES 1997). In fact, various studies have shown that the process of integration in the host society is positively correlated (or negatively when assimilation prevails over integration) with engagement in transnational mobility. Therefore, the discussion on transnational mobility today is closely related to patterns and processes of integration in the host society (VATHI 2015, p. 179). The recent introduction of the concept of integration as a three-way process (Garcés-Mascareñas and Penninx 2016, p. 2) represents an effort to elaborate further on the role of the countries of origin as a third key actor in the process of migrants' integration. In the same line of thought, two relatively recent theoretical approaches have incorporated the perspective of migrants' countries of origin: transnationalism and the migration-development nexus.

At this point, the question is how the concept of integration is defined in the context of this study. Does it endorse the plurality of different socio-cultural realities as well as the dynamics of transnational links, or does it remain in a separate sphere of national ideologies? Furthermore, exploring integration in two different contexts (countries) would help to understand its impact (positive or negative) on transnational mobility and the sort of transfers that are pursued through it.

\section{Integration}

The concept of integration can be seen as the opposite of disintegration and/or segregation if observed from the perspective of urban space. In this classical sociological approach, integration refers to the shared beliefs and practices of social interaction in a given society. In a way, integration is conceived as a term derived from social and political theory, which has dominated contemporary political debate about the incorporation of migrants (WEIL and CROWLEY 1994, p. 110). In the context of political science, integration is seen with reference to the influence of prevailing institutions in receiving countries, which orient the beliefs and actions of elite and mass actors regarding immigration and integration (TRIADAFILOPOULOS 2013, p. 23). 
Policy debates over integration, however, have taken place without any real agreement on what integration is. Some older approaches to the concept of integration are inclined to define it not only as a dynamic trajectory - a process towards a situation where socio-economic and political discrimination between demographically comparable immigrants and the native population is absent - but also as an objective. In that theoretical context, integration aims at ensuring the same living and working conditions as well as equal rights among native and migrant populations through the mutual adaptation of the two population groups during the integration process (HAMMAR 1985, p. 33). Thus, integration is perceived as a two-way process based on mutual rights and respective obligations for legally residing immigrants and the host country, a process that requires the full participation of migrants (C.E.C. 2003, pp. 18 f.). This means, first, that it primarily is the host country's responsibility to ensure that immigrants enjoy the same rights in a way that allows them to participate on equal terms in the economic, social, political, and cultural life of the receiving country. Secondly, it indicates that immigrants respect the host society's fundamental rules and values, and participate actively in the integration process, without relinquishing their ethnic identity. In practice, the use of the term integration refers to the acceptance and inclusion of the culturally different 'other' (i.e., migrant) within the dominant cultural system of the host country: this constitutes a fundamental mechanism for the reproduction of cultural codes and the integration of distinctive socio-cultural groups into a collective unit (Ventoura 2011, p. 38). From a dialectical point of view, BAUBÖCK (2001) maintains that integration "should be understood as referring to the inclusion of newcomers as well as to the internal cohesion of societies and political communities that are transformed by immigration" (p. 2). Going a step further, recently, the introduction of the concept of integration as a three-way process elaborates on the role of countries of origin as a third key actor in the process of migrants' integration (Garcés-Mascareñas and PenninX 2016, p. 2).

As is clear, integration cannot be seen as a single or unilinear process. Quite the opposite, it is a multi-dimensional process and it takes on different forms in time. In fact, integration is a broader concept that refers to a dynamic, continuous and multi-dimensional process, the success of which requires a two-way adaptation from both immigrants and host society, while considering the role of the sending state in these domains. Such an approach however recognizes the asymmetry it implies (ВАUВÖсK 2005, p. 18), since the institutional opportunity structures as well as the mechanisms of the state play the decisive role in the outcome of the process. Moreover, as immigration has become one of the more acute and controversial phenomena of (post-)modern times, its management at the national, regional and supranational levels remains a serious challenge. Either as immigrant receiving countries, countries of settlement, or as transit states, governments are increasingly seeking out new political tools to handle this extremely complex, controversial and multi-dimensional phenomenon effectively.

In fact, migration has extensively been discussed within the framework of the nation state. Having said that, integration policies are by virtue context-bound and entail 
two components: the ideological and the institutional (PEnNInx 2004, p. 21). With the state as a point of departure, the problem of ideological orientation is expressed in the definition of integration and the design of respective policies. In this vein, two policy models have been distinguished: the inclusionary and the exclusionary. The first refers to immigrants becoming citizens, with state policies recognizing immigrants as individual political actors (France), or to immigrants being recognized as citizens, but in this case ethnic minorities (as social groups) being conceptualized as relevant role players (AngloAmerican multiculturalism). The second refers to guest-worker policies, according to which the country is not an immigrant country, immigrants are defined as outsiders and hence are considered to be temporary workers (German and Austrian model) (Penninx 2004, p. 7). Therefore, the formation of social integration policies for immigrants appears to be linked directly to the tradition and history of each nation state, which developed in the course of the process of the establishment of the identity of the state. Thus, any form of integration is determined by the way that citizenship is perceived. Whether defined formally or in real terms, citizenship in liberal democratic societies means ensuring the individual's rights to participation in society. This refers both to the laws and to the institutions of a political system, which determine social interaction and the actors that take part in it. Meanwhile, it is clear that the common approaches that guide research on integration are concentrated in the dialectical interaction and in the interplay between top-down and bottom-up approaches. In claiming this, one at the same time acknowledges the key role of national opportunity to the positive or negative outcome of the social integration process. However, while acknowledging that national differences will not disappear, JOPPKE (2007) argues that they will persist in two ways, first "as sheer contingency and history, which will never be the same in any two places" and second, in nation state efforts "to obstruct, but more often to accommodate and mould the new in the image of the past" (JOPPKE 2007, p. 272). In other words, the suggestion is that one should distinguish between political and a-political integration. According to this, political integration adopts the perspective of the host country's national identity and historically derived conceptions of social membership. A-political integration, on the other hand, as is expressed by EU policy norms and directives, focuses on depoliticizing integration (in FANNING 2009, p. 44).

\section{Transnationalism}

In the last decade, the idea of transnationalism has been connected to further issues such as citizenship, integration and return migration. Transnationalism transcends the assimilationist assumptions of earlier migration research (DuNN 2005) to shed light on the ties and activities developed between individual, collective, and governmental actors located in two or more countries, mostly in immigrants' sending and destination countries. Theories on transnationalism transcend the earlier static assumptions in migration and integration research, aiming at shedding light on the bonds and practices developed between individual, collective, and governmental actors located in two or 
more countries (mostly focused on sending and receiving countries). As such, transnationalism has looked at the role of sending states, which admittedly have increasingly sought to strengthen relations with migrant populations abroad, facilitating their return (and reintegration) or paving the ground for their economic and political engagement in the country of origin (ØSTERGAARD-NiELSEN 2016).

The question however is how the term 'transnationalism' is conceptualized and empirically operationalized. The term delineates social formations spanning national borders, such as transnationally active networks, groups and organizations (FAIST 2010, p. 9), which involve simultaneous overlapping affiliations of persons to geographically separate polities (BAUBÖCK 2002, p. 5). It also refers to multiple ties and interactions linking people and institutions across the borders of nation states (VERTOVEC 1999, p. 447). Another feature central to the analysis of transnational social formations are structures or systems of relationships best described as networks (FAIST 2010). Dense and highly active networks spanning vast spaces are transforming many kinds of familial, social, cultural, economic and political relationships, with new technologies being at the heart of today's transnational networks. In more practical terms, transnationality is defined by cross-border social and symbolic bonds and practices maintained by individuals and households (FAUSER et al. 2012, p. 4). In this context, transnationalism refers to migrants' multi-stranded relationships, including the familial, economic, social, religious, and political, which span borders and link societies of origin and settlement (KING et al. 2013, p. 127).

Scholars have placed the transnational mobility of immigrants in the framework of the integration discourse, where national integration policies as well as citizenship regimes are considered as systemic opportunity structures that may encourage, discourage, or shape the degrees and types of immigrants' economic, political and social-cultural involvement in transnational activities. However, over time, as the process of social integration deepens, transnationalism decreases, unless the presence of favourable conditions develops forms of advanced transnationalism (AMBRosini 2014, p. 16). In contrast to this approach, other studies (CELA et al. 2013) showed a positive relationship between migrants' economic integration and transnationalism, suggesting that economic resources facilitate the maintenance and development of cross-border ties (2013, p. 195). Taking a broader contextual perspective, GLICK SCHILler et al. (1995, p. 50) support that being transnational is related to three basic factors: the history of immigration and modes of reception in the host country, migrants' cultural resources, and the discrimination faced by an immigrant group. At the individual level, the forms and intensity of transnational engagement are assumed to be further conditioned by variables such as gender, social class, migration channel, legal status and economic means (VATH 2015, p. 119), which are simultaneously related to community structure and political circumstances in the country of origin (VERTOVEC 2009).

At the same time, the phenomenon of discrimination and socio-economic exclusion of migrants in countries of settlement can also lead to the reproduction of 
transnational mobility (FAIST 2010). As such, migrants may face different opportunity structures in their homeland and host country, and may move up or down the ladder in respect to one of the two, or experience downward or upward mobility in both of them (LeVITT and JAWORSKY 2007, p. 139). For instance, most well educated Albanian migrants experience de-skilling and devaluation of their human capital because they are only able to access low-status jobs in destination countries, notably Greece (VATHI 2015 , p. 120). In this context, transnationality may play a role in producing and reproducing social inequalities that are understood in terms of inequality of opportunities in various forms of capital (economic, cultural and social), rather than in terms of outcome (FAIST 2011). From this perspective, migrants' economic, political and socio-cultural engagement in transnational activities are seen as an alternative strategy to cope with the risk of downward mobility (FAUSER et al. 2012, p. 10), as well as an attempt to create an environment that protects against the discrimination and marginalization commonly found in the host society (PoRTES 1999, p. 471). This latter option, termed 'reactive transnationalism', implies that the greater the number of experiences of discrimination reported, the greater the participation in transnational activities (ItZIGSOHN and Giorguli SAUCEDO 2005, p. 904).

Following the above line of reasoning, it is suggested that maintaining transnational mobility is sometimes considered to reflect a deeper level of (legal and economic) integration, or conversely to be a reaction to experiences of exclusion (negative integration) and discrimination. In the first case, previous studies (FAIST 2000; ITZIGSOHN and Giorguli SAUCEDo 2002) have shown a clear positive relationship between transnationalism and economic integration, whereas in the latter case, the reactive transnational mobility is seen as a reaction to experiences of legal and social exclusion (de-regularisation and unemployment) and discrimination in a time of deep crisis. Therefore, a positive relationship between exclusion (negative integration) and transnationalism is also assumed. In particular, exclusion and disadvantage in time of deep crisis (e.g., Greece) are thought to be related to transnational orientation, although it is acknowledged that different migrant groups may adopt diametrically opposed strategies.

\subsection{Methodological considerations}

From a migration system perspective, the basic units of analysis would be a country-to-country comparison that can be strategically employed to explore both the contextual and the human agency factors, such as for instance the institutional architecture and policy orientation along with the specific characteristics of migrants' agency. Such an approach is usually structured on the basis of a typological combination of a constellation of countries (sending and receiving) that constitutes a specific migration sub-system. This typological combination usually compares sub-systems that include: (a) Receiving countries that have the same sending area as for example the case of Albanians-to-Greece and Albanians-to-Austria. (b) Country-to-country sub-systems that 
have the same destination country, such as the case of Albanians-to-Italy or Romaniansto-Italy. (c) Destination areas that belong to the category of EU and non-EU countries as in the case of Germany and Switzerland (Audebert and Kamel Dorai 2010, p. 35).

Against this background, the analytical approach of this study is based on the argument that the complex processes of integration and transnationalism take place within the EU-Western Balkans migration that fall under the typological paradigm of EU receiving countries - Austria and Greece, sharing migrants from the same sending area, namely Albania.

In order to explore the diptych of integration vis-à-vis transnationalism, it was necessary to adopt a multi-level perspective, which elaborates on three levels: micro, meso, and macro. The micro-level perspective views migrants as independent actors, as agents within a constellation of increased cross-border flows of persons (FAIST 2010). The meso -level probes into the relational structures and networks (mainly that of family) that individual migrants develop through their transnational patterns, whereas the macro level analyses the broader national frameworks within which the dynamics of integration and transnational mobility develops. In an attempt to bridge these levels in a functional way, our approach builds on the hypothesis that macro-level migration processes are driven by a set of economic and non-economic factors, while on a micro level, the acts of migrants' agency are motivated by a constellation of interconnected but yet distinct socio-economic, cultural and political factors (DE HAAS 2012, p. 14).

The margin within which individuals can exercise their own agency however is largely dependent on the context and related structural factors that define the space within which individuals can make independent and rational choices. The question arising here is how these diametrically opposing levels of explanation, notably structure/ context (macro level) and agency (micro level), can be linked together? Whereas the latter focuses on micro factors that shape migration behaviour (i.e. perception, preferences, individual characteristics), the first perceives migrants as rather passive actors whose actions are conditioned by opportunity structures (DE HAAS 2012, p. 22). It is the meso -level that indicated the existence of an in-between space linking the macro and micro levels through the formation of migrant networks (FAIST 1997). As has already been discussed in section 1.1, a number of feedback mechanisms exists that can explain why migration processes tend to become self-perpetuating, leading to the formation of migrant networks and migration systems (CASTLES and Miller 2009; DE HaAs 2010). At this point, the challenge that the tri-dimensionality or multi-level analytical approach poses is the question of designing a representative comparative research framework. At first sight, the most practical level to enter upon is that of the statistical administrative data that is often used by researchers. It is commonly accepted that the cross-national comparison of such data is profoundly problematic (PENNINX 2010, p. 28), since no unified data collection and processing methodology exists. The national ideology on the general perception and formal construction of migrant or minority categories is even more important, however. A very characteristic example is the approach applied by the 
Municipality of Vienna according to which the variable of nationality or ethnicity should not be included in integration monitoring data, so as to avoid the social stigmatization of certain migrant groups just because they happen to appear statistically less integrated than others (Interview no. 6, Vienna). On the basis of the above and in line with the present case study, the theoretical part of the study draws on the two key concepts of integration and transnationalism. The typology employed to explore and test them empirically is as follows: Integration is conceptualized as a three-way process, which includes the country of destination, the country of origin, and migrants themselves. It is explored on the basis of three dimensions: (a) the legal-political, (b) the socio-economic, and (c) the cultural-religious.

Transnationalism is defined as a social-economic and political network spanning the national borders (of Austria and Greece), which involves simultaneous and overlapping affiliations of persons to geographically separate polities, and which links people and institutions across the borders of nation states. The typology applied identifies three forms of transnationalism: (a) linear, (b) resource dependent, and (c) reactive transnationalism (Itzigsohn and Giorguli Saucedo 2002).

In terms of empirical research, the main concern was determining the research design and sampling techniques that would ultimately support our main goal, which is to compare the same ethnic group within different national and local contexts, but at the same time to shed light on factors that explain differences. With these points of reference, the starting point of this study is the analysis of processes of integration and transnationalism as well as related policies on two different levels, the local and the national, based on an empirical, comparative, and comprehensive approach that takes into account different relevant dimensions. Furthermore, qualitative methods aid the understanding of intentions and social meanings, even though it cannot measure the frequency of individuals' attitudes and behaviours accurately. Case studies and relevant research tools present real people and their narratives, while offering the context through their constructions of social relevance (VARGAS-SILVA 2012, p. 15).

As a broader set of methods based on the qualitative approach, ethnography is particularly effective in exploring socio-economic integration processes with special regard to everyday life experience and it social relevance as well as the meaning underlying the 'construction' of realities. Similarly, ethnography is equally appropriate to explore not only transnational connections, but also the social dynamics through which they are established, evolved and transformed. In addition, it is highly relevant since it can shed light on the relationships that exist between 'structure, agency and geographic context' (HERBERT 2000, p. 550) by revealing the 'processes and meanings' that underpin social life across space. The multi-sited perspective is an ethnographic perspective akin to integration and transnational studies (VARGAS-SiLVA 2012, p. 305). Following people, connections, associations, and relationships across space is the focus of multi-sited research (ibid., p. 298). 
With these in mind, the methodology of the empirical part relies on multi-sited ethnographic fieldwork, comprising of 30 semi-structured interviews conducted in two phases with stakeholders and key informants in Athens (2016) and Vienna (2018). The ethnographic multi-sited approach was highly relevant for this study, since its revealing of the 'processes and meanings' that underpin social life across space and time can shed light on the relationships that exist between 'structure, agency and geographic context' (Herbert 2000, p. 550). This approach entails doing serial ethnographies on the same topic over time, and/or working simultaneously upon a communal concern in a multisited way (ibid., p. 312). In this context, this study adopted a comparative perspective involving three countries: Austria and Greece as destination countries and Albania as a country of origin. The only method, that was applied was that of snowball sampling, ensuring that a random sample has been selected.

The first set of 15 interviews was conducted in Athens in 2016 (see Annex 2). The sample included Albanian migrants of the first generation and representatives of the Albanian community in Greece. These categories allow us to explore in depth the multilevel schemes that shape the integration dynamics and mobility patterns of Albanians in Greece, precipitated by the impact of economic crisis on their livelihood. The sample includes representatives from the Municipality of Athens, civil society stakeholders, individual migrants, migrant community representatives, as well as UNHCR and other experts. The second set of 15 interviews took place in Vienna in 2018 (see Annex 1). The sample includes representatives of the Municipality of Vienna, civil society stakeholders, migrant community representatives, individual migrants, and experts from the ISR, IOM, FRA, and ICMPD.

The interview guide contained questions about integration as experienced from different social and professional positions (i.e. in the role of the migrant from a community and/or receiving country perspective) and in different contexts. Further questions dealt with the impact of a given context on the integration trajectory, the mode of integration, the motivations for becoming transnationally mobile, the factors that facilitated or impeded transnational mobility either in Albania or in destination countries, and the type of transfers carried out. 